\title{
Epithelial P2X purinergic receptor channel expression and function
}

\author{
Amanda L. Taylor, ${ }^{1,2}$ Lisa M. Schwiebert,${ }^{1,2,3}$ Jeffrey J. Smith, ${ }^{4}$ Chris King, ${ }^{2}$ Julie R. Jones, ${ }^{2,5}$ \\ Eric J. Sorscher, ${ }^{2,3,5}$ and Erik M. Schwiebert ${ }^{1,2,3}$ \\ ${ }^{1}$ Department of Cell Biology, \\ ${ }^{2}$ Gregory Fleming James Cystic Fibrosis Research Center, and \\ ${ }^{3}$ Department of Physiology and Biophysics, University of Alabama-Birmingham, Birmingham, Alabama 35294, USA \\ ${ }^{4}$ Department of Pediatrics, University of Iowa College of Medicine, Iowa City, Iowa 52242, USA \\ ${ }^{5}$ Department of Medicine, University of Alabama-Birmingham, Birmingham, Alabama 35294, USA \\ Address correspondence to: Erik M. Schwiebert, Gregory Fleming James Cystic Fibrosis Research Center, \\ University of Alabama-Birmingham, BHSB 740, 1918 University Boulevard, Birmingham, Alabama 35294-0005, USA. \\ Phone: (205) 934-6234; Fax: (205) 934-1445; E-mail: eschwiebert@phybio.bhs.uab.edu.
}

Received for publication May 6, 1999, and accepted in revised form August 23, 1999.

\begin{abstract}
P2X purinergic receptor (P2XR) channels bind ATP and mediate $\mathrm{Ca}^{2+}$ influx -2 signals that stimulate secretory $\mathrm{Cl}^{-}$transport across epithelia. We tested the hypotheses that $\mathrm{P} 2 \mathrm{XR}$ channels are expressed by epithelia and that P2XRs transduce extracellular ATP signals into stimulation of $\mathrm{Cl}^{-}$ transport across epithelia. Electrophysiological data and mRNA analysis of human and mouse pulmonary epithelia and other epithelial cells indicate that multiple P2XRs are broadly expressed in these tissues and that they are active on both apical and basolateral surfaces. Because P2X-selective agonists bind multiple $\mathrm{P} 2 \mathrm{XR}$ subtypes, and because $\mathrm{P} 2 \mathrm{X}$ agonists stimulate $\mathrm{Cl}^{-}$transport across nasal mucosa of cystic fibrosis (CF) patients as well as across non-CF nasal mucosa, P2XRs may provide novel targets for extracellular nucleotide therapy of CF.
\end{abstract}

J. Clin. Invest. 104:875-884 (1999).

\section{Introduction}

Extracellular nucleotide signaling affects epithelial cell function. There are 2 subtypes of ATP, or purinergic (P2), receptors. Nucleotides can bind to either P2Y G protein-coupled receptors or $\mathrm{P} 2 \mathrm{X}$ ion channel-forming receptors. Through either of these purinergic receptor subtypes, ATP is able to stimulate an increase in intracellular $\mathrm{Ca}^{2+}(1-3)$. P2Y receptors (P2YRs) couple to phospholipase $\mathrm{C}$, leading to production of inositol-1,4,5-triphosphate $\left(\mathrm{IP}_{3}\right)$ and mobilization of $\mathrm{Ca}^{2+}$ from internal stores (2). P2X receptors (P2XRs) form $\mathrm{Ca}^{2+}$-permeable nonselective cation channels that allow $\mathrm{Ca}^{2+}$ influx from extracellular stores $(3,4)$.

P2YRs are expressed by epithelia (5-7). Hints in the literature solidify our hypothesis that P2XR channels may be expressed, and have physiological importance, in epithelia. Korngreen et al. showed the presence of ATPgated cation currents reminiscent of P2XR channels in freshly isolated rabbit airway ciliated epithelial cells (8). The identity of the P2XR channels in these rabbit airway ciliated cells was not determined. Expression of P2X4 and P2X6 receptor isoforms in bronchial epithelium has been shown by in situ hybridization $(3,9)$. Filipovic et al. have identified a porcine P2X1-like isoform on LLC-PK1 renal epithelia (10). P2XR expression has also been documented in mouse proximal and collecting duct epithelial cell lines (11).

A detailed molecular and physiological characterization of P2XR channels in epithelial cells derived from the lung, airways, and gastrointestinal system has not been undertaken. P2XR channels have no sequence homology with any other ion channel family. However, P2XR channels share striking topological similarity to the epithelial sodium channels; each of these channel families is thought to form heteromultimeric channel complexes $(3,12)$. The results of this study provide physiological and molecular biological evidence that epithelia express multiple P2XR channels. Because P2XR is expressed in both epithelia of cystic fibrosis (CF) patients and in non-CF epithelia, derived from multiple CF-relevant tissues, P2XRs may provide an alternative - and perhaps more effective - target for extracellular nucleotide agonist therapy currently in development for the treatment of CF.

\section{Methods}

Cell culture. Epithelial cell lines and primary cultures were grown on Vitrogen 100-coated tissue-culture plastic and filter supports (Collagen Corp., Palo Alto, California, USA). Epithelial cell lines from lung and gastrointestinal tract were grown as described previously (13). Primary cultures of large and small airway epithelial cells (purchased from Clonetics Corp., a division of BioWhittaker, San Diego, California, USA) were grown in a BEBM (Clonetics Corp.) containing insulin $(10 \mu \mathrm{g} / \mathrm{mL})$, transferrin $(5 \mu \mathrm{g} / \mathrm{mL})$, EGF $(25 \mathrm{ng} / \mathrm{mL})$, bovine pituitary extract $(5 \mu \mathrm{g} / \mathrm{mL})$, hydrocortisone $(1 \mu \mathrm{M})$, triiodothyronine $(30 \mathrm{nM})$, and cholera toxin $(10 \mathrm{ng} / \mathrm{mL})$. Cultures were supplemented with $1 \times$ penicillin-streptomycin, $1 \times$ L-glutamine, $1 \times$ gentamicin, and $1 \times$ Fungizone $($ GIBCO 

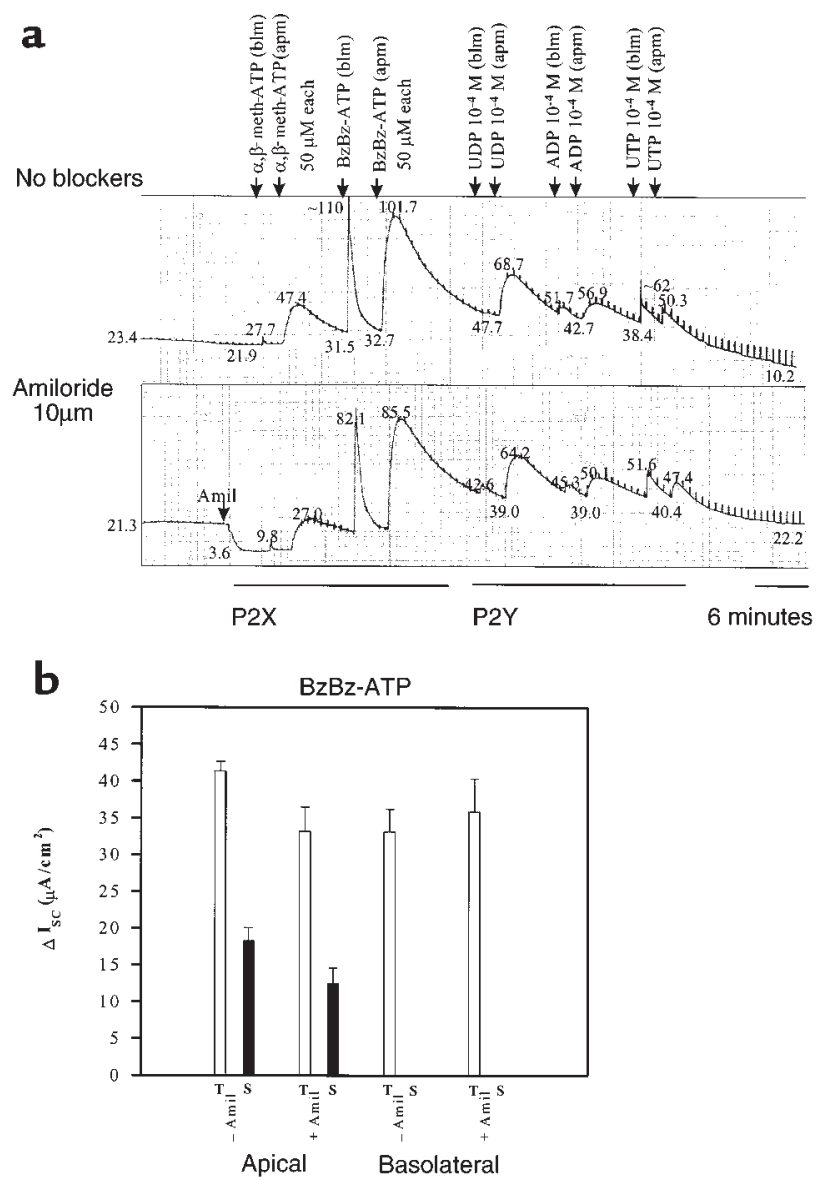

Figure 1

Apical (apm) and basolateral (blm) P2X agonists stimulate Isc across mouse tracheal epithelial monolayers grown in primary culture. (a) Parallel recordings with and without apical amiloride are shown. Measured current values (in $\mu \mathrm{A} / \mathrm{cm}^{2}$ ) are shown at points along each record. P2YR-selective agonists were also tested in these experiments. No washing of agonists was performed. (b) Data summary of transient $(T)$ and prolonged $(S) I_{S C}$ stimulated by the agonist, BzBz-ATP. $n=4$ with and without amiloride. All stimulated current was significant $(P<0.005)$. Similar effects were obtained in experiments with $\alpha, \beta$-meth-ATP.

BRL, Grand Island, New York, USA). Primary cultures of normal rat cholangiocytes (biliary epithelial cells) were grown as described previously $(14,15)$. Primary cultures of mouse non-CF tracheal epithelial monolayers were grown on filter supports in Ham's F12 7× medium containing insulin $(10 \mu \mathrm{g} / \mathrm{mL})$, transferrin $(5 \mu \mathrm{g} / \mathrm{mL})$, EGF $(25 \mathrm{ng} / \mathrm{mL})$, endothelial cell growth supplement (5 $\mu \mathrm{g} / \mathrm{mL})$, hydrocortisone $(1 \mu \mathrm{M})$, triiodothyronine (30 $\mathrm{nM})$, and cholera toxin $(10 \mathrm{ng} / \mathrm{mL})$. These cultures were supplemented with Dulbecco's MEM containing 10\% FBS conditioned by 3 T3 fibroblasts. Human non-CF airway epithelial primary cultures, grown as monolayers, were grown as described previously $(16,17)$.

Macroscopic physiological assays

Whole-cell patch-clamp recording. Whole-cell recordings were designed to study ATP-gated, nonselective cation currents in non-CF and CF epithelial cells. The pipette (intracellular) solution contained (in $\mathrm{mM}$ ): 145 potassium gluconate, 10 HEPES, 0.1 calcium gluconate, 0.1 magnesium gluconate, and 2 EGTA; $\mathrm{pH}$ was 7.45 . The bath (extracellular) solution contained (in $\mathrm{mM}$ ): 145 sodium gluconate, 60 sucrose, 10 HEPES, 1 calcium gluconate, and 1 magnesium gluconate; $\mathrm{pH}$ was 7.45. ATP, as a P2XR agonist, was added to the bath in paired experiments, as was the P2XR antagonist suramin. Sucrose was added to the bath to balance osmolality, because intracellular protein contributes to the intracellular osmolality and does not dilute after formation of the whole-cell configuration. A voltage-pulse protocol that began with a holding voltage $(0 \mathrm{mV})$ and had steps between $-100 \mathrm{mV}$ and $+100 \mathrm{mV}$ at 20 - $\mathrm{mV}$ increments was used, driven by PClamp 6.0 software, a Digidata 1200 motherboard, and an A/D interface between PClamp 6.0 and a Gateway P5-166 personal computer (Gateway 2000, N. Sioux City, South Dakota, USA). An Axopatch 200B patch-clamp amplifier (Axon Instruments, Foster City, California, USA) clamped the voltage and drove the voltage-pulse protocol through a CV203BU headstage amplifier attached to a BurleighNewport patch-clamp manipulator system (Burleigh Instruments, Fishers, New York, USA).

Ussing chamber recording. Primary cultures of mouse and human non-CF airway epithelial monolayers were studied that have a high electrical resistance (mouse: $>1,000 \Omega \cdot \mathrm{cm}^{2}$; human: $>500 \Omega \cdot \mathrm{cm}^{2}$ ), are well differentiated, and have a ciliated apical membrane. This high resistance is achieved over 8-14 days on collagencoated Transwell filters $6 \mathrm{~mm}$ in diameter (CorningCostar Corp., Corning, New York, USA). Substantial positive $\left(>20 \mu \mathrm{A} / \mathrm{cm}^{2}\right)$ transepithelial short-circuit current $\left(\mathrm{I}_{\mathrm{SC}}\right)$ and negative transepithelial voltage (more negative than $-10 \mathrm{mV}$ ) are observed routinely in these monolayers under basal conditions. For mouse tracheal monolayers, 4 monolayers were studied simultaneously in 4 parallel Ussing chambers interfaced with 2 Ussing chamber amplifiers. Nucleotides were added to either side of the monolayer and were not washed from the chamber at any time during the 1-2-hour recording. The same was true of amiloride, $\mathrm{Cl}^{-}$channel inhibitors, bumetanide, and barium chloride $\left(\mathrm{BaCl}_{2}\right)$. The bathing solution for these studies was PBS $(\mathrm{pH}$ 7.45; purchased from Life Technologies Inc., Grand Island, New York, USA) containing $1 \mathrm{~g} / \mathrm{L}$ glucose and $5 \mathrm{mM}$ HEPES. These methods have been published for human airway epithelial monolayers $(18,19)$.

Nasal potential difference measurements. Lactated Ringer's solution was instilled into the nasal passages, and an electrode was placed into the nose of wild-type or cystic fibrosis transmembrane conductance regulator-knockout (CFTR-knockout) mice while the tail was placed in a vessel of Ringer's to serve as the ground. A 3-step protocol was used in these nasal potential difference (PD) recordings. First, nasal PD was measured until stable in lactated Ringer's solution containing amiloride to inhibit $\mathrm{ISC}_{\mathrm{SC}}{ }^{\mathrm{Na}}$. Then amiloride in a lactated Ringer's solution with low $\mathrm{Cl}^{-}$ was circulated into the mouse nose and measured until 
stable. Finally, P2XR agonists were added to low-ClRinger's solution containing amiloride in order to evaluate activation of $\mathrm{Cl}^{-}$transport across the nasal mucosa.

Degenerate RT-PCR and differential DNA sequencing. Epithelial cell total RNA was extracted with Trizol reagent (GIBCO BRL) according to the manufacturer's protocol. Total RNA was reverse-transcribed, and degenerate RTPCR of P2XR cDNA was performed by standard methods.

Amplification was performed on the following sequences: actin A: 5'-TGACGGGGTCACCCACACTGTGCCCATCTA-3'; actin B: 5'-CTAGAAGCATTGCGGTGGACGATGGAGGG-3' $\left(60^{\circ} \mathrm{C}\right.$ annealing temperature); P2XR degenerate A: 5'-TTCACCMTYYTCATCAARAACAGCATC3'; and P2XR degenerate B: 5'-TGGCAAAYCTGAAGTTGWAGCC- $3^{\prime}\left(52^{\circ} \mathrm{C}\right.$ annealing temperature).

PCR products were retrieved from agarose gel slices using a QIAquick gel extraction kit (Qiagen Inc., Santa Clarita, California, USA). Once purified, PCR products were ligated into the pGEM-T vector system (Promega Corp., Madison, Wisconsin, USA), which is specialized for subcloning PCR products. Ligations were transformed into JM109-competent cells (Promega Corp.), and the transformations were plated on LB-agar plates containing ampicillin $(100 \mu \mathrm{g} / \mathrm{mL}), \mathrm{X}$-gal $(40 \mu \mathrm{g} / \mathrm{mL})$, and IPTG $(100 \mu \mathrm{g} / \mathrm{mL})$ for ampicillin selection of successful transformants and for blue/white selection of successful insertion. White colonies were picked off the plate to inoculate a 6-mL LB growup with continued ampicillin selection. The pGEM-T plasmid with insert was purified using a PerfectPrep miniprep kit (5 Prime 3 Prime, Boulder, Colorado, USA). The purified PCR product insert was sequenced using the Sequenase dideoxy termination method (USB Corporation, Cleveland, Ohio, USA) using $\left[\alpha-{ }^{35} \mathrm{~S}\right] \mathrm{dATP}$ (NEN Life Science Products Inc., Boston, Massachusetts, USA). The resulting DNA sequence was read by 2 independent investigators and was screened with the basic local alignment search tool (BLAST) algorithm (20) to determine whether it was a known or novel sequence.

\section{Results}

P2XR channels are expressed in mouse airway epithelia

$P 2 X R$ agonists stimulate ion transport across mouse non-CF tracheal epithelia. The P2XR-specific agonists $\alpha, \beta$-methyleneadenosine- $5^{\prime}$-triphosphate $(\alpha, \beta$-methATP) and $2^{\prime}$ - and $3^{\prime}$-O-(4-benzoyl-benzoyl)-adenosine-5' $5^{\prime}$-triphosphate (BzBz-ATP) were added to physiological assays of well-differentiated epithelial monolayers to stimulate P2XRs, to

Table 1

\section{Table 2}

detect the presence of P2XRs in the plasma membrane, and to assess the physiological relevance of P2XRs in airway epithelia in vitro and in vivo. To assess polarity of P2XR expression in airway epithelia, P2XR agonists were added to the apical or basolateral side of the epithelium. Ussing chamber recordings measured ion transport or $\mathrm{I}_{\mathrm{SC}}$ across the epithelium. Figure 1a shows a matched pair of monolayers studied simultaneously in the absence and presence of apical amiloride $(10 \mu \mathrm{M})$. Amiloride-inhibited $\mathrm{I}_{\mathrm{SC}}{ }^{\mathrm{Na}}$ was observed in mouse tracheal epithelial monolayers grown in primary culture (Figure 1a). In this epithelial model, basal or baseline ISC was supplied by $\mathrm{Cl}^{-}$secretion, $\mathrm{ISC}_{\mathrm{SC}}{ }^{\mathrm{Cl}}$ and $\mathrm{Na}^{+}$absorption, or $\mathrm{I}_{\mathrm{SC}}{ }^{\mathrm{Na}}$ (see examples in Figures $1 \mathrm{a}$ and $2 \mathrm{a}$ ). In the absence or presence of amiloride, addition of $\alpha, \beta$-meth$\operatorname{ATP}(50 \mu \mathrm{M})$ to either the basolateral or apical membrane stimulated an increase in current. BzBz-ATP (50 $\mu \mathrm{M}$ ) had the greatest stimulatory effect on current. (Figure 1a). Basolateral addition of P2X agonists stimulated an immediate, transient increase in $\mathrm{I}_{\mathrm{SC}}$. In comparison, apical addition of $\mathrm{P} 2 \mathrm{X}$ agonists stimulated $\mathrm{I}_{\mathrm{SC}}$ that had a slower onset of activation, was greater in magnitude, and had an additional, more prolonged component (Figure 1a). Figure $1 \mathrm{~b}$ shows summarized results in response to basolateral and apical BzBz-ATP. Responses to the

Incidence of P2XR isoform sequences in lung-derived epithelial cells

\begin{tabular}{|c|c|c|c|c|c|c|c|}
\hline Cell line or primary culture & $\mathrm{P} 2 \mathrm{X} 2$ & $\mathrm{P} 2 \mathrm{X} 3$ & $\mathrm{P} 2 \mathrm{X} 4$ & $\mathrm{P} 2 \mathrm{X} 5$ & $\mathrm{P} 2 \mathrm{X} 7$ & "P2XL" & $\begin{array}{l}\text { Total } \\
\text { minipreps }\end{array}$ \\
\hline $16 \mathrm{HBE} 14 \mathrm{o}^{-}$ & & & 11 & 8 & & 4 & 23 \\
\hline Calu-3 & & & 10 & 9 & & 1 & 20 \\
\hline 9HTEO ${ }^{-}$ & & 19 & 1 & & & & 20 \\
\hline NHSAE primary & & & 9 & 3 & & & 12 \\
\hline CFNP primary & & & 2 & 10 & 8 & 1 & 21 \\
\hline $\mathrm{CFBE} 1 \mathrm{o}^{-}$ & 21 & & & & 2 & & 23 \\
\hline$\Sigma$ CFTE-29o- & & 2 & 6 & 12 & 4 & & 24 \\
\hline Beas2B & & & 2 & 8 & & & 10 \\
\hline
\end{tabular}

All cell lines and primary cultures were described in the text. Numbers are based on the best alignment of a sequence by BLASTN analysis. P2X 4 and P2X5 are shown in bold to illustrate shared high incidence among the airway epithelial cell models.

Incidence of P2XR isoform sequences in gastrointestinal tract-derived epithelial cells

\begin{tabular}{|c|c|c|c|c|c|c|}
\hline Cell line or primary culture & P2X1 & $\mathrm{P} 2 \mathrm{X} 2$ & $\mathrm{P} 2 \mathrm{X} 3$ & $\mathrm{P} 2 \mathrm{X} 4$ & P2X5 & $\mathrm{P} 2 \mathrm{XH}$ \\
\hline
\end{tabular}

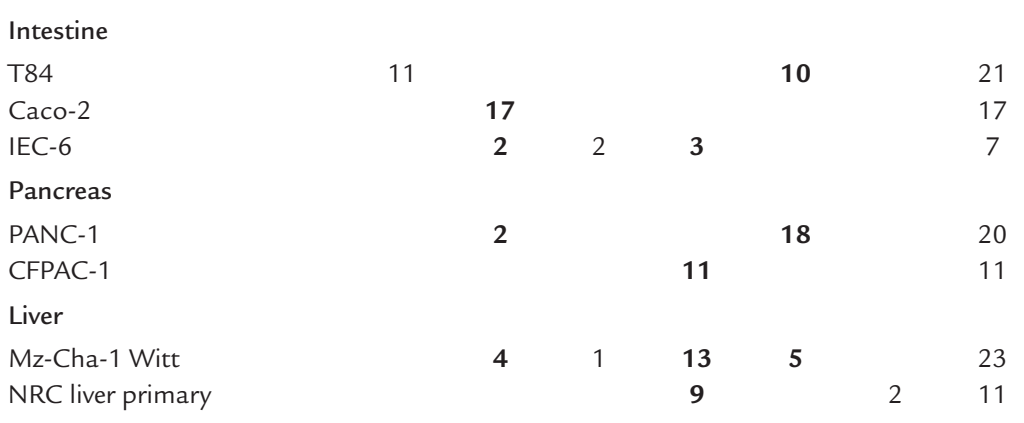

All cell lines and primary cultures were described in the text. Numbers are based on the best alignment of a sequence by BLASTN analysis. 
P2YR-selective agonists UDP, ADP, and UTP were also observed, which validates the integrity of the monolayer after 1 hour of recording. These results indicate that P2XR channel proteins are expressed on the apical and basolateral membranes of primary mouse non-CF tracheal epithelia. Also, P2XR agonists stimulate $\mathrm{I}_{\mathrm{SC}}$ across the epithelium in the presence of amiloride, suggesting that $\mathrm{P} 2 \mathrm{XRs}$ stimulate either $\mathrm{Cl}^{-}$secretion or amilorideinsensitive $\mathrm{Na}^{+}$absorption.

P2XRs stimulate current in a dose-dependent manner. $\mathrm{P} 2 \mathrm{XR}$ agonists stimulated ion transport when added to the apical and basolateral sides of the airway epitheli$\mathrm{um}$, and when added near or above the $\mathrm{ED}_{50}$ for known $\mathrm{P} 2 \mathrm{XR}$ isoforms (Figure 1). To assess the dose dependence of P2XR agonists, a different protocol was performed to assess responses to $1 \mu \mathrm{M}, 10 \mu \mathrm{M}$, and 100 $\mu \mathrm{M}$ doses of $\alpha, \beta$-meth-ATP or BzBz-ATP that were added to the basolateral and apical sides of primary mouse tracheal epithelial monolayers (Figure 2a). In the absence or presence of amiloride, basolateral addition of P2XR agonists stimulated an immediate, transient increase in $I_{S C}$ that was short-lived (see Figures 1a and 2a). Interestingly, as little as $1 \mu \mathrm{M}$ of basolateral BzBz-ATP stimulated a maximal increase in $\mathrm{I}_{\mathrm{SC}}$, whereas $100 \mu \mathrm{M}$ of $\alpha, \beta$-meth-ATP was required to observe a

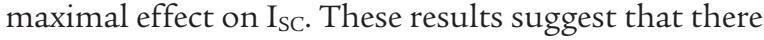
may be differences in P2XR expression and function between the apical and the basolateral membrane.

Two different P2XR agonists stimulate $\mathrm{Cl}^{-}$secretion in an additive manner. When added apically in graded doses, $\mathrm{P} 2 \mathrm{X}$ agonists stimulated a more prolonged (if not a sustained) increase in ISC (Figure 2a). Little transient component of the stimulated $\mathrm{I}_{\mathrm{SC}}$ was observed with this protocol. The $10 \mu \mathrm{M}$ dose of $\alpha, \beta$-meth-ATP stimulated ISC as well as or better than the $10 \mu \mathrm{M}$ dose of BzBz-ATP. The subtle differences in efficacy between the 2 P2XRspecific agonists again suggest that different P2XR isoforms may be expressed on the apical membrane than are expressed on the basolateral membrane. Apical stimulation of $\mathrm{I}_{\mathrm{SC}}$ by the $2 \mathrm{P} 2 \mathrm{XR}$ agonists in this protocol was additive (see Figure 2a for example). Importantly, in the presence of apical DIDS (4,4'-diisothiocyanato-stilbene2,2'-disulfonic acid, $100 \mu \mathrm{M}$ ) or apical DPC (diphenylamine carboxylate, $1 \mathrm{mM}$ ), 2 different broad-specificity $\mathrm{Cl}^{-}$channel-blocking drugs, $\mathrm{P} 2 \mathrm{XR}$ stimulation of $\mathrm{I}_{\mathrm{SC}}$ was markedly inhibited, suggesting that stimulated ISC reflects secretory $\mathrm{I}_{\mathrm{SC}}{ }^{\mathrm{Cl}}$ (Figure 2, a and b). Figure $2 \mathrm{~b}$ shows summarized results of each $\mathrm{P} 2 \mathrm{X}$ agonist alone or with apical amiloride, DIDS, or DPC. P2X agonist responses are also abolished by $100 \mu \mathrm{M}$ basolateral bumetanide (Figure 2b), an inhibitor of the basolateral $\mathrm{Na}^{+} / \mathrm{K}^{+} / 2 \mathrm{Cl}^{-}$cotransporter, and are inhibited by $100 \mu \mathrm{M}$ basolateral $\mathrm{BaCl}_{2}$, a broad-specificity $\mathrm{K}^{+}$channel blocker. This suggests that entry of $\mathrm{Cl}^{-}$across the basolateral membrane via the cotransporter, and hyperpolarization of the basolateral membrane through activation of the basolateral $\mathrm{K}^{+}$flux, also contribute to P2XR-mediated stimulation of $\mathrm{Cl}^{-}$secretion (Figure $2 \mathrm{~b}$ ). Forskolin stimulation of CFTR-mediated $\mathrm{I}_{\mathrm{SC}}{ }^{\mathrm{Cl}}$ was performed as a pos-
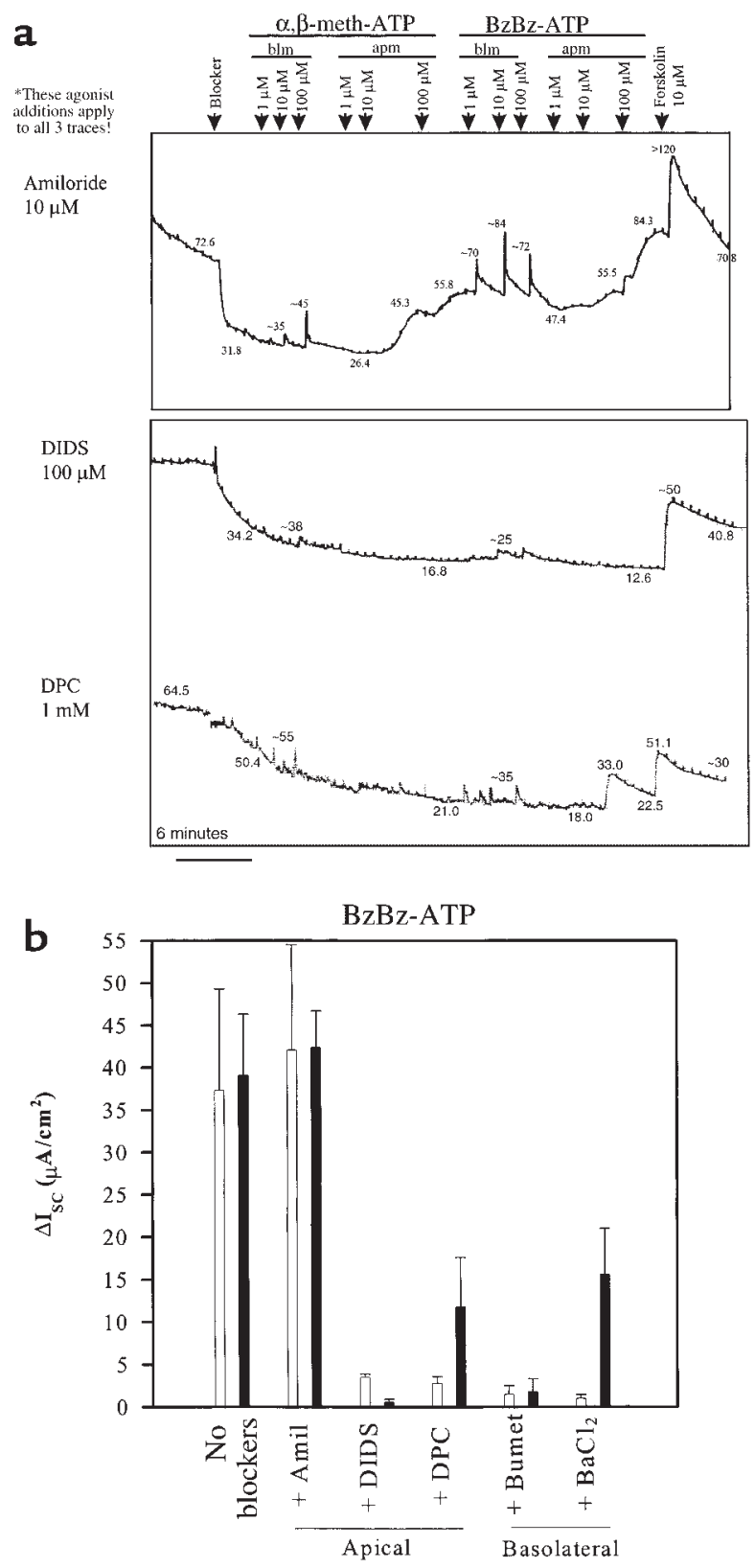

Figure 2

Apical (apm) and basolateral (blm) P2X agonists stimulate $\mathrm{I}_{\mathrm{SC}} \mathrm{Cl}^{\mathrm{C}}$ across mouse tracheal epithelial monolayers grown in primary culture. (a) Parallel recordings in the presence of apical amiloride, apical DIDS, and apical DPC. Forskolin was added as a positive control to stimulate CFTR-dependent $I_{S C}$ and to confirm the integrity of each monolayer. (b) Data summary showing effects of apical and basolateral blockers of ion transport on BzBz-ATP-stimulated Isc. $n=4$ with and without amiloride; $n=3$ for other blockers. All stimulated current was significant $(P<0.005)$. Similar effects were obtained in experiments with $\alpha, \beta$-meth-ATP. Amil, amiloride; Bumet, bumetanide.

itive control to validate the integrity of the monolayer after 1 hour of recording. Taken together, these results suggest that basolateral and apical P2XR agonists stimulate $\mathrm{Cl}^{-}$secretion across non-CF mouse tracheal epithelial monolayers. Stimulation of $\mathrm{Cl}^{-}$secretion is inhibited 


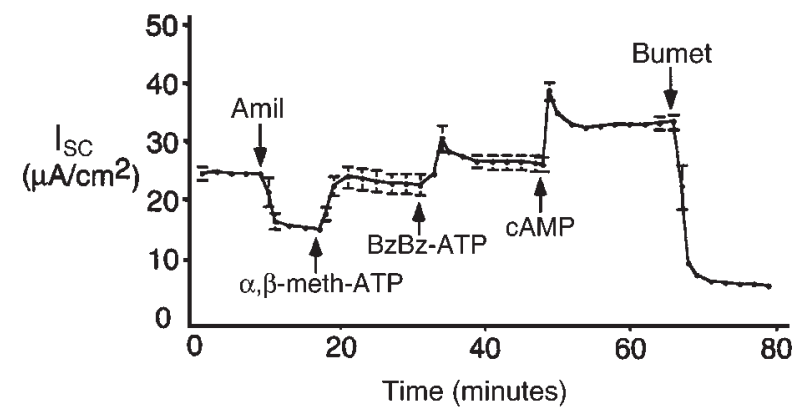

Figure 3

Apical P2X agonists stimulate $\mathrm{I}_{\mathrm{SC}} \mathrm{Cl}$ in an additive manner across human non-CF airway epithelial monolayers grown in primary culture. Mean \pm SEM of 3 recordings performed on human non-CF airway epithelial monolayers grown in primary culture. A cocktail containing forskolin, IBMX, and CAMP analogue (cAMP) was added as a positive control to stimulate CFTR-dependent $\mathrm{I}_{\mathrm{SC}}$ and to confirm the integrity of each monolayer. Bumetanide blocked approximately $90 \%$ of the stimulated secretory $\mathrm{Cl}^{-}$current. The residual current may be amiloride-insensitive $\mathrm{Na}^{+}$absorptive current (perhaps P2XR current itself). All effects of inhibitors and agonists were significant $(P<0.05)$.

or blocked by apical application of the $\mathrm{Cl}^{-}$channel blockers DPC and DIDS (but not by amiloride), and is inhibited by basolateral bumetanide and $\mathrm{BaCl}_{2}$, suggesting that $\mathrm{P} 2 \mathrm{XRs}$ potentiate $\mathrm{Cl}^{-}$secretion by stimulating $\mathrm{Cl}^{-}$ channels in the apical membrane, $\mathrm{K}^{+}$flux across the basolateral membrane, or both.

P2XR channels are expressed in human airway epithelia

P2XR agonists stimulate $\mathrm{Cl}^{-}$secretion across buman nonCF airway epithelia. To test the hypothesis that P2XRs were expressed and functional in human airway epithelial cells, P2XR-specific agonists were tested on monolayers of non-CF human airway epithelia grown in primary culture. Figure 3 shows the $\mathrm{I}_{\mathrm{SC}}$ response to sequential apical application of $\alpha, \beta$ meth-ATP, BzBz-ATP, and a cAMP-agonist cocktail. Note that apical amiloride $(10 \mu \mathrm{M})$ reduced $\mathrm{I}_{\mathrm{SC}}$ from approximately $25 \mu \mathrm{A} / \mathrm{cm}^{2}$ to $15 \mu \mathrm{A} / \mathrm{cm}^{2}$. Addition of apical $\alpha, \beta$-meth-ATP $(50 \mu \mathrm{M})$ stimulated a sustained increase in $\mathrm{I}_{\mathrm{SC}}$. Subsequent apical addition of BzBzATP $(50 \mu \mathrm{M})$ stimulated an additive and sustained increase in $\mathrm{I}_{\mathrm{SC}}$ above that of $\alpha, \beta$-meth-ATP alone. Agonists to cAMP $(10 \mu \mathrm{M}$ forskolin and $0.5 \mathrm{mM} 3$ isobutyl-1-methylxanthine [IBMX]) stimulated a small, additional increase in ISC $_{\mathrm{SC}}$ above that of the P2XR agonists. Bumetanide $(100 \mu \mathrm{M})$ inhibited virtually all of the stimulated ISC, suggesting that the $\mathrm{I}_{\mathrm{SC}}$ stimulated by P2XR agonists and cAMP agonists reflects $\mathrm{Cl}^{-}$secretion (Figure 3). Taken together, these results show that apical P2XR channels stimulate sustained $\mathrm{Cl}^{-}$secretion across non-CF human airway epithelia. As in mouse Ussing chamber experiments, the 2 different P2XR-specific agonists stimulated $\mathrm{Cl}^{-}$secretion in an additive manner.

P2XRs stimulate transepithelial $\mathrm{Cl}^{-}$transport across the nasal epithelium of wild-type and CFTR-knockout mice. Nasal
PD measurements assess ion transport across the nasal mucosa and validate the efficacy of an agonist as a putative $\mathrm{Cl}^{-}$secretagogue in vivo $(21,22)$. We performed nasal PD measurements to test the hypothesis that P2XRs are expressed on the apical or mucosal membrane and that P2XRs stimulate $\mathrm{Cl}^{-}$transport across the nasal epithelium.

$P 2 X R$ agonists stimulate $\mathrm{Cl}^{-}$secretion in vivo in wild-type mice. P2XR-specific agonists were tested for their ability to stimulate $\mathrm{Cl}^{-}$secretion in vivo. Experiments were performed in a manner similar to that of Middleton et al. (23). P2XR agonists were added in the presence of a low- $\mathrm{Cl}^{-}$solution containing amiloride. Under these conditions, when a $\mathrm{Cl}^{-}$gradient is established, a depolarized change in the nasal PD induced by the P2XR agonists alone or in a cocktail indicates an increase in $\mathrm{Cl}^{-}$permeability (likely reflective of $\mathrm{Cl}^{-}$secretion). Scatter-plot summaries of all measurements of wild-type mice show the trials that produced a significant change and those that caused no change in nasal PD (Figure 4a). No inhibitory effects were observed in any of the 25 mice used in the trials (Figure 4a). The statistical summary of the data shows that both P2XR agonists administered together $(\alpha, \beta$-meth-ATP + BzBz-ATP $=$ $\Delta 2.3 \pm 1.0 \mathrm{mV}, n=9)$ caused a greater change in PD than did each agonist alone (BzBz-ATP $=\Delta 1.3 \pm 0.4 \mathrm{mV}$, $n=8 ; \alpha, \beta$-meth-ATP $=\Delta 1.2 \pm 0.4 \mathrm{mV}, n=8)$ (Figure 4a). However, the additive effect of the cocktail did not result in an effect that was significantly different than that of each agonist alone. These results show that P2XR agonists added intranasally as in vivo agonists stimulate $\mathrm{Cl}^{-}$transport in wild-type mice.

$P 2 X R$ agonists stimulate $\mathrm{Cl}^{-}$secretion in vivo in CFTRknockout mice. For the P2XR agonists to be beneficial in restoring $\mathrm{Cl}^{-}$transport in $\mathrm{CF}$, they must induce $\mathrm{Cl}^{-}$ secretion in vivo in CF transgenic mice (23-25). To test this hypothesis, $\mathrm{P} 2 \mathrm{XR}$-specific agonists were tested in $\mathrm{CF} \Delta \mathrm{F} 508 / \Delta \mathrm{F} 508$ mice (26). BzBz-ATP induced a significant stimulation of $\mathrm{Cl}^{-}$secretory nasal $\mathrm{PD}$ responses (observed in 7 out of $7 \mathrm{CF}^{-1-}$ mice; Figure 4b). A scatter plot of the data from all $7 \mathrm{CF}^{-/-}$mice shows that responses to BzBz-ATP in the $\mathrm{CF}^{-/-}$mice were significantly greater $(\Delta 3.25 \pm 1.0 \mathrm{mV}, n=7)$ than in the wildtype mice $(\Delta 1.3 \pm 0.4 \mathrm{mV}, n=8)$ (Figure $4 \mathrm{~b}$ ). These results show that BzBz-ATP stimulates $\mathrm{Cl}^{-}$transport as well or better in nasal mucosa of CFTR-knockout mice than in nasal mucosa of wild-type mice. These results also suggest that P2XR agonists may prove useful in restoring $\mathrm{Cl}^{-}$secretion to airways in CF patients.

Molecular evidence for expression of multiple P2XR channel isoforms in epithelia. Little is known concerning which P2XR isoforms are expressed in epithelia. In the absence of available specific antibodies to P2XRs, a degenerate RT-PCR strategy was used to identify which P2XR isoforms were expressed at the highest levels in epithelial cell lines and primary cultures. An extensive panel of cell models derived from CF-afflicted tissues was gathered for this analysis, because early degenerate RT-PCR results showed that multiple P2XR isoforms are expressed by 


\section{Figure 4}

Mucosal P2X agonists stimulate secretory $\mathrm{Cl}^{-}$transport across wild-type and CFTR-knockout mouse nasal epithelia in vivo. (a) Data summary showing individual experiments (open ovals) and the mean \pm SEM values (filled ovals) from studies with each P2XR agonist and with both agonists added together as a cocktail. (b) Data summary showing comparison of effects of BzBz-ATP in CFTRknockout vs. wild-type (WT) mice. Shown are individual trials (open ovals) and mean \pm SEM (filled ovals). Steady-state nasal PD values are shown after addition of $\mathrm{P} 2 \mathrm{XR}$ agonist in low- $\mathrm{Cl}^{-}$solution with amiloride. Change in $\mathrm{PD}$ is a depolarization indicative of an increase in $\mathrm{Cl}^{-}$permeability; the change was significant in all cases $(P<0.05)$. a

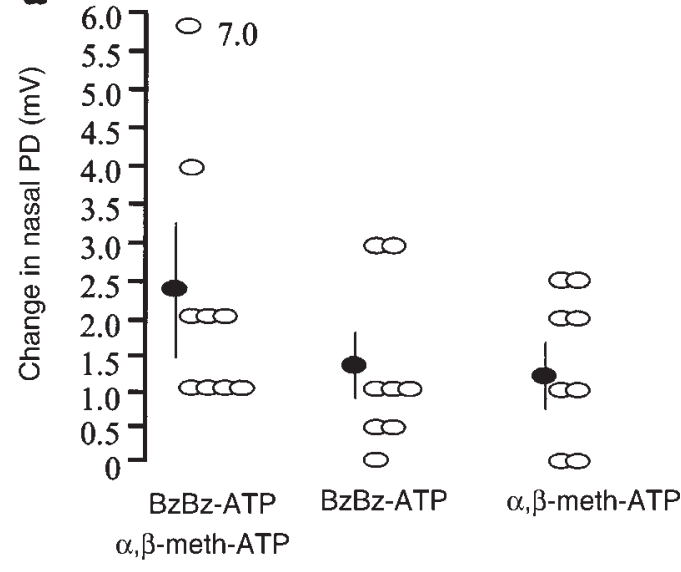

\section{WT}

b

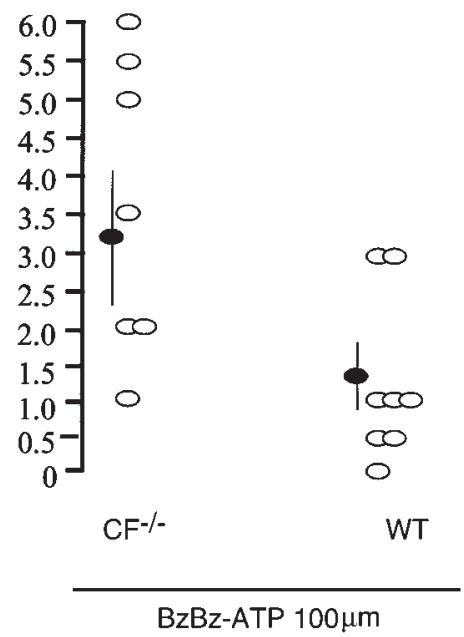

epithelial cells. Many cell lines and primary cultures were required to confirm that similar mixtures of $\mathrm{P} 2 \mathrm{XR}$ isoforms were shared by multiple epithelial cell models.

P2XR mRNA is detected in airway epithelial cells. Figure 5 shows the results of this analysis. Amplified P2XR PCR products of the expected size ( $330 \mathrm{bp}$ ) that were run in parallel are shown in a variety of human CF and nonCF epithelial cell lines and primary cultures derived from the lung, airways, and other tissues. Negative controls (without cDNA) and no-RT controls were negative for P2XR mRNA (Figure 5). Importantly, only 1 product of $330 \mathrm{bp}$ was amplified in all PCR reactions. Correlative RT-PCR from the housekeeping gene, $\beta$ actin (750-bp product), was also performed (data not shown) to authenticate the cDNA before degenerate P2XR PCR. These results suggest that mRNA for P2XRs is expressed by all lung and airway epithelial cell lines and primary cultures. Molecular data agree with functional data that revealed $\mathrm{P} 2 \mathrm{XR}$ protein expression at the epithelial plasma membrane.

P2X4 and P2X5 P2XR channel isoforms are expressed prevalently in non-CF and CF buman airway epithelia. What was unclear from the degenerate RT-PCR analysis was which P2XR isoforms were expressed by these epithelial cell models. To determine which P2XR genes were expressed in each epithelial RNA sample, differential DNA sequencing analysis was undertaken. P2XR DNA sequences of PCR products that matched 6 of the 7 cloned P2XR genes and 2 putative novel P2XR isoforms were obtained from this analysis of lung and gastrointestinal tract epithelia. Representative DNA sequences for the most common airway and lung P2XR sequences - P2X 4 and P2X 5 - are shown in Figure 6. These were amplified from a sample of total RNA from Calu-3 non-CF human submucosal gland serous cells. The BLAST nucleotide analysis algorithm (20) was used for each nucleotide sequence derived from each white colony. This was done to identify the particular P2XR isoform that most closely matched the PCR product sequence, and to differentiate the PCR product sequence from the other isoforms (see BLAST $P$ value for identity in Figure 6).

In the lung and airway samples (Table 1), multiple P2XR sequences were amplified. First, in a CF nasal polyp (CFNP) primary culture and a CF tracheal epithelial cell line ( $\Sigma \mathrm{CFTE}-29 \mathrm{o}^{-}$), as many as $4 \mathrm{P} 2 \mathrm{XR}$ isoforms were amplified. In both CFNP and $\Sigma$ CFTE-290 ${ }^{-}$cells, $\mathrm{P} 2 \mathrm{X} 5$ was found at the highest incidence. In a non-CF bronchial epithelial cell line (16HBE14o-), a non-CF submucosal gland serous cell line (Calu-3), a non-CF bronchial epithelial cell line (Beas2B), the CFNP primary culture, the $\Sigma \mathrm{CFTE}-290^{-} \mathrm{CF}$ cell line, and a nonCF human small airway epithelial cell primary culture (NHSAE), high levels of P2X5 and P2X4 were present. Moreover, a potentially novel P2XR isoform, P2XL, was identified in a subset of these airway and lung epithelial cells. Because P2XL was not found in samples from other tissues, it was determined to be a lung-specific, $\mathrm{P} 2 \mathrm{X}$-like sequence. P2X sequences for the P2X2 and $\mathrm{P} 2 \mathrm{X} 3$ isoforms were found exclusively and with high incidence in a $\mathrm{CFBE} 410^{-} \mathrm{CF}$ bronchial epithelial cell line and in a non-CF tracheal epithelial cell line (9HTEo-), respectively. $\mathrm{P} 2 \mathrm{X} 7$ was identified only in CF epithelial cell lines and primary cultures, with the highest incidence in the CFNP primary culture. P2XR PCR products were also amplified from an alveolar type II adenocarcinoma cell line, A549 (see Figure 5), from other CF airway epithelial cell lines (IB3-1 and CFT1), and from primary mouse and human airway epithelial primary cultures (data not shown). Taken together, these results suggest that multiple P2XR isoforms are expressed in epithelia derived from the small and large airways, the alveolus, and the submucosal glands of the lung. In particular, P2X4 and P2X5 are shared by airway epithelia. 
This analysis was also performed on epithelial cell mRNA derived from liver, intestine, and pancreas (Table 2). Four of the 7 gastrointestinal tract-derived epithelial cell lines expressed P2X2, including Caco-2, a human intestinal epithelial cell line; IEC-6, a rat embryonic intestinal epithelial cell line; PANC-1, a human pancreatic epithelial cell line; and Mz-Cha-1 Witt, a human biliary cholangiocarcinoma epithelial cell line. The T84 colon carcinoma cell line was the only cell line in this analysis to express the P2X1 isoform. This may reflect something unique about T84 carcinoma cell P2XR expression, because all other epithelial cells screened by the degenerate PCR analysis lacked P2X1. P2X3, P2X4, and P2X5 were also identified in multiple gastrointestinal epithelial cell lines. Six of the 7 gastrointestinal epithelial cell types expressed either P2X4 or P2X5, or both. These included T84 cells, IEC6 cells, Witt biliary cholangiocytes, PANC-1 cells, CFPAC-1 CF human pancreatic epithelial cells, and the normal rat cholangiocyte liver primary cultures. The $\mathrm{Mz}$-Cha-1 liver epithelial cell line expresses at least 4 different P2XR channel isoforms, P2X2 through P2X5. Taken together, these results suggest that multiple $\mathrm{P} 2 \mathrm{XR}$ isoforms are expressed by epithelia derived from the bile ducts of the liver, the pancreas, and the intestine. Of importance to eventual therapeutic development of P2XR-specific agonists in lung and gastrointestinal tract, poorly desensitizing $\mathrm{P} 2 \mathrm{XR}$ isoforms (P2X2, P2X4, and P2X5) are expressed at the highest incidence in these CF-relevant epithelia.

Airway epithelial P2XRs function as ATP-gated nonselective cation channels. Whole-cell patch-clamp recordings were designed to study ATP-gated, nonselective cation currents in non-CF and CF epithelial cells (Figure 7a) shows current-voltage (I-V) relationships for basal cur-

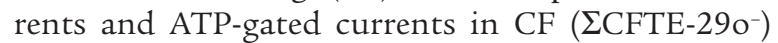
human tracheal epithelial cells. ATP stimulates linear, nonselective cation currents significantly in non-CF and CF cells at the 10- $\mu \mathrm{M}$ dose (Figure 7a). Moreover, the reversal potential of the I-V plots was at or near 0 $\mathrm{mV}$, indicating that these whole-cell cation currents were nonselective for $\mathrm{Na}^{+}$vs. $\mathrm{K}^{+}$(Figure 7a). An example of the time-dependent stimulation of ATP-gated cation currents is also shown (Figure 7b). In a $\Sigma$ CFTE$29 \mathrm{o}^{-}$cell recording, currents were sustained and did not desensitize after several minutes (Figure 7b). ATP-gated currents were also blocked by the P2XR antagonist suramin ( $30 \mu \mathrm{M}$; see Figure $7 \mathrm{~b}$ for a typical example), validating that currents measured in whole-cell experiments were conducted by P2XR channels. Finally, Figure $7 \mathrm{c}$ shows a data summary of recordings in which P2XR currents were stimulated by 2 - to 3 -fold by $10 \mu \mathrm{M}$ ATP in 3 different airway epithelial cell models in response to different doses of ATP agonist. Comparison of the results from a matched pair of non-CF (9HTEo $)$ and CF ( $\Sigma$ CFTE-29o-) epithelial cells reveals that P2XR currents are stimulated in both models and that the current density is similar in magnitude (the membrane capacitance, or membrane area, of these cells is similar: $20 \mathrm{pF}$ in 9HTEo cells and $22 \mathrm{pF}$ in $\Sigma$ CFTE-290- cells). Taken together, these results also show that P2XR channels are expressed in the plasma membrane and function as ATP-gated, nonselective cation channels in non-CF and CF airway epithelia.

\section{Figure 5}

P2XR mRNA is expressed in human CF and non-CF airway epithelial cell lines and in primary cultures. (a) P2XR PCR products from $16 \mathrm{HBE} 14 \mathrm{o}^{-}$non-CF human bronchial epithelial cells, CFBE410- CF human bronchial epithelial cells, $\Sigma$ CFTE-29o- CF human tracheal epithelial cells (shown in b), a CFNP epithelial primary culture, Calu-3 non-CF human submucosal gland serous cells, and human umbilical vein endothelial cells (HUVEC). NC, no cDNA (control). (b) Comparison of positive airway epithelial cell reactions to T84 non-CF human colon carcinoma cells and PANC-1 non-CF human pancreatic epithelial cells. (c) Positive reactions from the $16 \mathrm{HBE} 14 \mathrm{o}^{-}$sample compared with CFPAC-1 CF human pancreatic epithelial cells, IMCD renal inner medullary collecting-duct cells, and HUVEC. (d) Positive reactions for A549 non-CF human alveolar lung cells and Beas2B non-CF human bronchial epithelial cells vs. control (No RT). Positive reactions for CFPAC-1 and 16HBE140- cells are also shown as positive controls for comparison. Beas2B 1 and Beas2B 2 are two different cDNA samples from the same RNA sample. (e) PCR controls on 16HBE140- total RNA sample. No P2XR PCR product was derived from amplification of total RNA (-/-) or RNase-free, DNase-treated total RNA (DNase), whereas positive reactions occurred in total RNA reverse-transcribed to cDNA with (DNase/RT) and without (RT) DNase treatment. All amplifications of epithelial cell samples were performed 2-3 times. Note: Analysis of the sites that the degenerate P2X PCR primers recognized within the genomic sequence of the mouse P2X3 gene (28) indicated that our primers spanned at least 2 introns; amplification of genomic DNA would produce a PCR product at least $2 \mathrm{~kb}$ larger than the 330-bp expected size. Moreover, in the P2X3 genomic sequence, our reverse primer spanned an exon/intron boundary (intron $\sim 25 \mathrm{~kb}$ in size), rendering amplification of genomic DNA improbable. 
PCR Product ATTTCACCCTTTTCATCAAGAACAGCATCTGGTATCCCAAATTTAATTTCAGCAAGAGGAATATCCTTCCCAACAT hP2X4R ACTTCACTCTTTT GGTTAAGAACAACATCTGGTATCCCAAATTTAATTTCAGCAAGAGGAATATCCTTCCCAACAT 578

132

PCR Product CACCACTACTTACCTCAAGTCGTGCATTTATGATGCTAAAACAGATCCCTTCTGCCCCATATTCCGTCTTGGCAAA

hP2X4R CACCACTACTTACCTCAAGTCGTGCATTTATGATGCTAAAACAGATCCCTTCTGCCCCATATTCCGTCTTGGCAAA $\begin{array}{ll}654 & 729\end{array}$

208

282

PCR Product ATAGTGGAGAACGCAGGACACGGTTTCCAGGACATGGCCGTGGAGGGAGGCATCATGGGCATCCAGGTCAA

hP2X4R ATAGTGGAGAACGCAGGACACAGTTTCCAGGACATGGCCGTGGAGGGAGGCATCATGGGCATCCAGGTCAACTG 730

283

339

PCR Product GGACTGCAACCTGGACAGAGCCGCCTCCCTCGACTTTA CCAGGTACTCCTTTCGTAGC

hP2X4R GGACTGCAACCTGGACAGAGCCGCCTCCCTC TGCTTGC CCAGGTACTCCTTCCGCCGC 805

861

BLASTN score $=2.5 \times 10^{-96}$

b

Calu-3 P2X5 cDNA probe sequence

26

PCR Prod. TTCACCCTTCTCATCAAGAACAGCATCCGTTTGCCCAAATTCAACTTCTCCAACAATGTGATGGACGTCAAGGACAG

hP2X5R TTCACCATT TTCATAAAGAACCACATCCGTTTCCCCAAATTCAACTTCTCCAACAATGTGATGGACGTCAAGGACAG 542

81

PCR Product ATCTTTCCTGAAATCATGCCACTTTGGCCCCAAGAACCACTACTGCCCCATCTTCCGACTGGGCTCCGTGATCCGC hP2X5R ATCTTTCCTGAAATCATGCCACTTTGGCCCCAAGAACCACTACTGCCCCATCTTCCGACTGGGCTCCGTGATCCGC 619

140

199

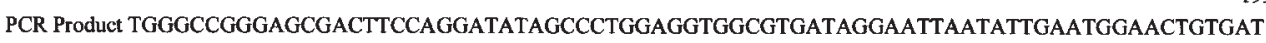

hP2X5R TGGGCCGGGAGCGACTTCCAGGATATAGCCCTGGAGGTGGCGTGATAGGAATTAATATTGAATGGAACTGTGAT 653

712

$200 \quad 247$

PCR Product CTTGATAAAGCTGCCTCTGAGTGCCACCCTCACTATTCTTTTAGCCGTCTGGACAATAAACTTTCAAAGTC

hP2X5R CTTGATAAAGCTGCCTCTGAGTGCCACCCTCACTATTCTTTTAGCCGTCTGGACAATAAACTTTCAAAGTC 772

BLASTN score $=3.7 \times 10^{-107}$

\section{Figure 6}

Representative P2X4 and P2X5 cDNA probe sequences. Nucleotides in bold are differences between our PCR products and the published GenBank sequence. BLASTN score of identity is shown for each sequence. Tables 1 and 2 reflect the number of sequences in all cell models screened that were identified as P2X4 (a) or P2X5 (b). Sequences derived from degenerate RT-PCR of a Calu-3 total RNA sample are shown. A BLASTN score that is more negative in its exponent reflects a high degree of sequence identity.

\section{Discussion}

This study represents a thorough characterization of P2XR channels in an extensive panel of epithelial cell models relevant to CF by physiological and molecular biological methods. Because we found ample functional and molecular evidence that multiple P2XR channel isoforms are expressed in epithelial cell lines and primary cultures, this work suggests that multiple P2XR channels are expressed on the apical and basolateral membranes of proximal and distal airways, submucosal glands of the airway, and alveolar cells. Moreover, it is likely that P2XRs are also expressed in pancreas, liver, and intestine. In agreement with our work, Korngreen et al. have shown electrophysiological evidence of cation channels reminiscent of $\mathrm{P} 2 \mathrm{XRs}$ in freshly isolated and ciliated rabbit airway epithe- lial cells (8). In situ hybridization studies have shown evidence of staining in bronchial epithelium for P2X 4 and P2X6 $(3,9)$. P2X 4 was also found in salivary gland $(3,9)$. The fact that our results also find P2X4 in epithelial cells from lung, airways, gastrointestinal tract, and from a Calu-3 cell line derived from submucosal gland are in agreement with that previous work. Our study shows abundant expression of P2X5 in epithelia, which to our knowledge is a novel result. We have not found P2X6 in any epithelial cell model thus far, suggesting that the in situ hybridization signal for $\mathrm{P} 2 \mathrm{X} 6$ may reflect cross-reactivity with another P2X isoform, perhaps P2X5.

P2XRs may provide a series of novel target molecules on both membranes of exocrine epithelia in the airways (both lower and upper) and in submucosal glands of the 
Figure 7

Extracellular ATP (Ext ATP) stimulates nonselective cation currents in wholecell recordings of non-CF and CF airway epithelial cells. (a) I-V plots of basal and ATP-stimulated nonselective cation currents in LCFTE-29o- cells. $n=6$, paired recordings. Values are mean \pm SEM $\left({ }^{*} P<\right.$ 0.05). (b) Typical time course of sustained P2XR current stimulation with 2 doses of ATP ligand, and reversal with suramin, a P2XR antagonist. (c) Data summary of ATP ligand stimulation of P2XR current in 3 human airway epithelial cell models. $n=$ 4-6 among the 3 airway epithelial cell models. Sim-

ilar data was obtained using T84 cells (data not shown). (d) Patch-clamp icon illustrates the experimental design, where the pipette (intracellular) solution contains $140 \mathrm{mM}$ potassium gluconate (KGlu) and the bath (extracellular) solution contains $145 \mathrm{mM}$ sodium gluconate ( $\mathrm{NaGlu}$ ). In this design, whole-cell currents are nonselective for cations if the reversal potential is at or near $0 \mathrm{mV}^{-}$. Substitution of $\mathrm{Cl}^{-}$with Glu- eliminates the chance that ATP agonists would stimulate an epithelial $\mathrm{Cl}^{-}$channel, a possibility that is probably based on the preliminary data above. Moreover, Glu- also chelates divalent cations, such as $\mathrm{Ca}^{2+}$ and $\mathrm{Mg}^{2+}$, that may block P2XR channels.

airway, intestine, pancreatic duct, and biliary duct for extracellular nucleotide therapy of CF. Moreover, the $\mathrm{P} 2 \mathrm{XR}$ isoforms found in the highest incidence were $\mathrm{P} 2 \mathrm{X} 4, \mathrm{P} 2 \mathrm{X} 5$, and $\mathrm{P} 2 \mathrm{X} 2$. These isoforms do not desensitize as readily in neurons, muscle cells, or heterologous expression systems as do P2X1 or P2X3 (3, 9). Our functional results in epithelia suggest that they fail to desensitize altogether. The fact that desensitization may be lacking or mild in these isoforms only enhances the therapeutic benefit of these receptor agonists.

The function of P2XRs in epithelia may not be limited to stimulation of $\mathrm{Cl}^{-}$secretion across epithelial barriers. Under physiological conditions, it is likely that the predominant ionic flux through these channels is $\mathrm{Ca}^{2+}$ influx down the profound $\mathrm{Ca}^{2+}$ gradient. $\mathrm{Na}^{+}$ movement into the cell and $\mathrm{K}^{+}$movement out of the cell may cancel each other out, although this may depend on the magnitude of the apical or basolateral membrane potential. Nevertheless, changes in membrane potential caused by P2XR-mediated fluxes and capacitative $\mathrm{Ca}^{2+}$ entry through P2XR channels may affect many epithelial functions through intracellular $\mathrm{Ca}^{2+}$ signaling such as vesicle trafficking, protein secretion, and signal-transduction pathways that depend on $\mathrm{Ca}^{2+}$. Of interest to P2XR action and to P2XR-targeted therapy, the sustained responses of currents in response to 1 or more applications of P2XR agonists suggests a sustained intracellular signaling mechanism beyond or independent of increases in intracellular $\mathrm{Ca}^{2+}$ alone. Because all types of receptors desensitize by

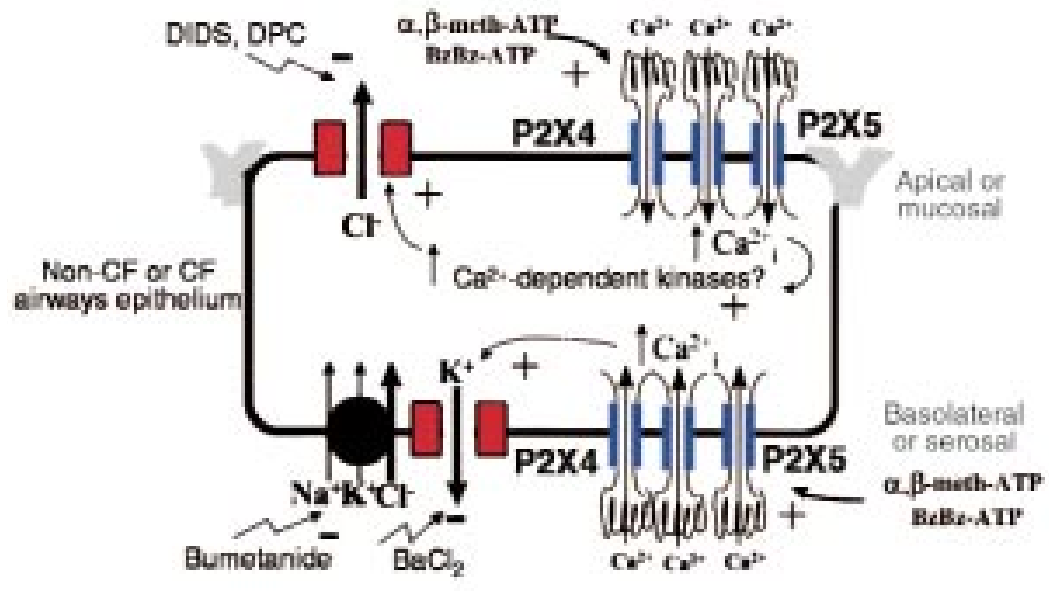

Figure 8

Model of P2XR channel expression and function in non-CF or CF airway epithelium. The model is reflective of either a non-CF or CF airways epithelium. P2XR channels are expressed on both the apical and basolateral membranes. They probably form heteromultimeric complexes of P2X4 and P2X5, based on our molecular expression data; however, additional isoforms have been detected in some epithelial cell lines. The electrophysiological and signaling mechanisms whereby P2XRs may stimulate $\mathrm{Cl}^{-}$secretion are shown in the apical and basolateral membrane domains. $\mathrm{Ca}^{2+}$-mediated signaling is probable; however, additional unappreciated signaling mechanisms may be involved that are triggered by P2XRs. 
1 or more mechanisms, it will be important to define the signaling pathways that P2XR channels affect. Tarasiuk et al. and Korngreen et al. have also shown that extracellular ATP may enhance ciliary beat frequency in a P2XR-dependent manner $(8,27)$. Enhancement of ciliary beat would also be beneficial for mucociliary clearance therapy in CF.

Taken together, these data demonstrate that P2XR channels are expressed on both the apical and basolateral membranes of well-differentiated mouse and human airway epithelia grown in primary culture (Figure 8). P2XRs in both membranes stimulate secretory $\mathrm{Cl}^{-}$transport across airway epithelia. In the basolateral membrane, P2XR channels may allow ATPgated $\mathrm{Ca}^{2+}$ influx which may be directly coupled to basolateral $\mathrm{K}^{+}$channels (Figure 8). Activation of basolateral $\mathrm{K}^{+}$channels would enhance the electrical driving force for $\mathrm{Cl}^{-}$secretion across the apical membrane, because the apical and basolateral membrane voltages are coupled electrically. Agonists of basolateral $\mathrm{K}^{+}$ channels have been argued to have therapeutic benefit for CF patients through this cellular mechanism; we may have found such an agonist in this study. In the apical membrane, P2XR channels may also allow ATPgated $\mathrm{Ca}^{2+}$ influx that would stimulate $\mathrm{Ca}^{2+}$-sensitive $\mathrm{Cl}^{-}$channels, either directly through an increase in intracellular $\mathrm{Ca}^{2+}$ or indirectly through stimulation of $\mathrm{Ca}^{2+}$-dependent protein kinases (Figure 8). In particular, P2XRs in the mucosal membrane of wild-type and CFTR-knockout mice enhance $\mathrm{Cl}^{-}$permeability of the nasal mucosa, suggesting that P2XRs may be viable targets for extracellular nucleotide therapy in CF. Correlative molecular biological analysis shows that multiple P2XR channel isoforms are expressed by human non-CF and CF airway and gastrointestinal epithelia. This study lays the groundwork for future studies of epithelial P2XRs in lung, gastrointestinal tract, and other tissues lined with epithelia.

\section{Acknowledgments}

We thank Jim Collawn and Kevin Kirk for evaluating our manuscript, and Bruce Stanton for evaluating aspects of the data. Other members of the laboratory who helped technically with the large number of minipreps and the extensive DNA sequencing analysis for P2XR PCR products were Jeffrey Hovater, Gavin Braunstein, Brian Kudlow, and Kevin Marrs. Amanda Taylor is supported by a Predoctoral Training Grant from the Cellular and Molecular Biology Graduate Program at the University of Alabama-Birmingham. This work was funded by the Cystic Fibrosis Foundation (CFF) and American Lung Association New Investigator Awards to Lisa Schwiebert, a CFF New Investigator Award and a Research Grant to Erik Schwiebert, the CF Center Research Development Program, and a CFF Research Grant to Jeffrey J. Smith.
1. Abbracchio, M.P., and Burnstock, G. 1994. Purinoceptors: are there families of $\mathrm{P}_{2 X}$ and $\mathrm{P}_{2 Y}$ purinoceptors? Pharmacol. Ther. 64:445-475.

2. Barnard, E.A., Burnstock, G., and Webb, T.E. 1994. G protein-coupled receptors for ATP and other nucleotides: a new receptor family. Trends Pharmacol. Sci. 15:67-70.

3. Buell, G., Collo, G., and Rassendren, F. 1996. P2X receptors: an emerging channel family. Eur. J. Neurosci. 8:2221-2228.

4. Bean, B.P. 1992. Pharmacology and electrophysiology of ATP-activated ion channels. Trends Pharmacol. Sci. 13:87-90.

5. Parr, C.E., et al. 1994. Cloning and expression of a human $\mathrm{P}_{2 \mathrm{U}}$ nucleotide receptor, a target for cystic fibrosis pharmacotherapy. Proc. Natl. Acad. Sci. USA. 91:3275-3279

6. Lazarowski, E.R., Paradiso, A.M., Watt, W.C., Harden, T.K., and Boucher, R.C. 1997. UDP activates a mucosal-restricted receptor on human nasal epithelial cells that is distinct from the P2Y2 receptor. Proc. Natl. Acad. Sci. USA. 94:2599-2603.

7. Nicholas, R.A., Watt, W.C., Lazarowski, E.R., Li, Q., and Harden, T.K. 1996. Uridine nucleotide selectivity of three phospholipase C-activating P2 receptors: identification of a UDP-selective, a UTP-selective, and an ATP- and UTP-specific receptor. Mol. Pharmacol. 50:224-229.

8. Korngreen, A., Ma, W., Priel, Z., and Silberberg, S.D. 1998. Extracellular ATP directly gates a cation-selective channel in rabbit airway ciliated epithelial cells. J. Physiol. (Lond.) 508:703-720.

9. Collo, G., et al. 1996. Cloning of P2X5 and P2X6 receptors and the distribution and properties of an extended family of ATP-gated ion channels. J. Neurosci. 16:2495-2507.

10. Filipovic, D.M., Adebanjo, O.A., Zaidi, M., and Reeves, W.B. 1998. Functional and molecular evidence for P2X receptors in LLC-PK1 cells. Am. J. Physiol. 274:F1070-F1077.

11. Takeda, M., Kobayashi, M., and Endou, H. 1998. Establishment of a mouse clonal early proximal tubule cell line and outer medullary collecting duct cells expressing P2 purinoceptors. Biochem. Mol. Biol. Int. 44:657-664.

12. Canessa, C.M., et al. 1994. Amiloride-sensitive epithelial $\mathrm{Na}^{+}$channel is made of three homologous subunits. Nature. 367:463-467.

13. Taylor, A.L., et al. 1998. Bioluminescence detection of ATP release mechanisms in epithelia. Am. J. Physiol. 275:C1391-C1406.

14. McGill, J., Basavappa, S., Shimokura, G.H., Middleton, J.P., and Fitz, J.G. 1994. ATP activates ion permeabilities in biliary epithelial cells. Gastroenterology. 107:236-243.

15. Roman, R.M., et al. 1997. Hepatocellular ATP-binding cassette protein expression enhances ATP release and autocrine regulation of cell volume. J. Biol. Chem. 272:21970-21976.

16. Yamaya, M., Finkbeiner, W.E., Chun, S.Y., and Widdicombe, J.H. 1992. Differentiated structure and function of cultures from human tracheal epithelium. Am. J. Physiol. 262:L713-L724.

17. Zabner,J., Smith, J.J., Karp, P.H., Widdicombe, J.H., and Welsh, M.J. 1998. Loss of CFTR chloride channels alters salt absorption by cystic fibrosis airway epithelia in vitro. Mol. Cell. 2:397-403.

18. Smith, J.J., and Welsh, M.J. 1992. Cyclic AMP stimulates bicarbonate secretion across normal but not cystic fibrosis airway epithelia. J. Clin. Invest. 89:1148-1153.

19. Zabner, J., Couture, L.A., Smith, A.E., and Welsh, M.J. 1994. Correction of cyclic AMP-stimulated fluid secretion in cystic fibrosis airway epithelia: efficiency of adenovirus-mediated gene transfer in vitro. Hum. Gene Ther. 5:585-593.

20. Altschul, S.F., Gish, W., Miller, W., Myers, E.W., and Lipman, D.J. 1990. Basic local alignment search tool (BLAST). J. Mol. Biol. 215:403-410.

21. Schwiebert, E.M., and Guggino, W.B. 1997. Abnormal chloride and sodium channel function in cystic fibrosis airway epithelia. In The lung: scientific foundations. R.G. Crystal, P.J. Barnes, J.B. West, and E.R. Weibel, editors. Lippincott-Raven Publishers. New York, NY. 2555-2572.

22. Knowles, M.R., Clarke, L.L., and Boucher, R.C. 1992. Extracellular ATP and UTP induce chloride secretion in nasal epithelia of cystic fibrosis patients and normal subjects in vivo. Chest. 101:60-63.

23. Middleton, P.G., Geddes, D.M., and Alton, E.W. 1994. Protocols for in vivo measurement of the ion transport defects in cystic fibrosis nasal epithelium. Eur. Respir. J. 7:2050-2056.

24. Dorin, J.R., and Porteous, D.J. 1992. Cystic fibrosis mice with diseaserelated changes in lung and reproductive tract. Lancet. 340:984.

25. Dorin, J.R., et al. 1996. A demonstration using mouse models that successful gene therapy for cystic fibrosis requires only partial gene correction. Gene Ther. 3:797-801.

26. Ratcliff, R., et al. 1993. Production of a severe cystic fibrosis mutation in mice by gene targeting. Nat. Genet. 4:35-41.

27. Tarasiuk, A., et al. 1995. Extracellular ATP induces hyperpolarization and motility stimulation of ciliary cells. Biophys. J. 68:1163-1169.

28. Souslova, V., et al. 1997. Structure and chromosomal mapping of the mouse P2X3 gene. Gene. 195:101-111 